\title{
Decreasing Liftoff Height Behavior in Diluted Laminar Lifted Methane Jet Flames
}

\author{
Kyuho Van ${ }^{1}$, Ki Sung Jung ${ }^{2}$, Chun Sang Yoo ${ }^{2}$, Soohyun $\mathrm{Oh}^{1}$, Byeong Jun Lee ${ }^{3}$, \\ Min Suk Cha ${ }^{4 *}$, Jeong Park ${ }^{1 *}$, Suk Ho Chung ${ }^{4}$ \\ ${ }^{1}$ Department of Mechanical Engineering, Pukyong National University, Busan, Korea \\ 2 Department of Mechanical Engineering, Ulsan National Institute of Science and Technology, \\ Ulsan, Korea \\ ${ }^{3}$ School of Mechanical Engineering, Yeungnam University, Daegu, Korea \\ ${ }^{4}$ Clean Combustion Research Center (CCRC), King Abdullah University of Science and \\ Technology (KAUST), Thuwal, Saudi Arabia
}

\begin{abstract}
Stabilization of laminar lifted coflow jet flames of nitrogen-diluted methane was investigated experimentally and numerically. As the fuel jet velocity was increased, two distinct behaviors in liftoff height were observed depending on the initial fuel mole fraction; a monotonically increasing trend and a decreasing and then increasing trend (U-shaped behavior). The former was observed in the jet-developing region and the latter in the jetdeveloped region. Because the decreasing behavior of liftoff height with jet velocity has not been observed at ambient temperature, the present study focuses on decreasing liftoff height behavior. To elucidate the physical mechanism underlying the U-shaped behavior, numerical simulations of reacting jets were conducted by adopting a skeletal mechanism. The U-shaped behavior was related to the buoyancy. At small jet velocities, the relative importance of the buoyancy over convection was strong and the flow field was accelerated in the downstream region to stabilize the lifted flame. As the jet velocity increased, the relative importance of buoyancy decreased and the liftoff height decreased. As the jet velocity further increased, the flame stabilization was controlled by jet momentum and the liftoff height increased.
\end{abstract}

Keywords: Buoyancy; coflow jet; edge flame; laminar flame; lifted flame 


\section{Introduction}

The stabilization of lifted flames is an important issue for their practical application. Lifted flames in laminar jets have been studied extensively to identify the flame stabilization mechanism [1-6], which have been linked to turbulent lifted flames through a laminar flamelet formulation [7]. The base of a laminar lifted flame exhibits a tribrachial (or triple) structure, consisting of lean and rich premixed flame wings and a trailing diffusion flame, all extending from a single location. This type of flame has been observed in various flame configurations [8-15].

A tribrachial structure dictates that the flame in a jet is stabilized along a stoichiometric contour and the propagation speed is balanced with the local axial flow velocity. The propagation speed is dependent on many factors, such as mixture strength, concentration gradient, buoyancy, flow redirection effect, heat losses, and Schmidt number. When one (or more) of these is changed, the anchoring location is altered to re-balance the flame $[1-6,8-$ 12] and occasionally oscillates [13-18]. The balance of the propagation speed of tribrachial flames and axial flow velocity in nonpremixed jets results in excellent experimental and theoretical correlations between the liftoff height and jet velocity in free jets $[1,2]$. A correlation of the propagation speed of tribrachial flames to the flame curvature was identified in laminar lifted free and coflow jet flames [4, 5].

Research has revealed that for cold free jets, liftoff height increases with fuel jet velocity and a lifted flame is stable (unstable) for fuel Schmidt numbers $\left(\mathrm{Sc}_{\mathrm{F}}\right)$ larger ( $\mathrm{smaller}$ ) than unity in free jets $[1,2]$. Lifted flames can be stable theoretically even for $\mathrm{Sc}_{\mathrm{F}}<1$ [19], which was verified experimentally for methane jet flames diluted with $\mathrm{He}$ or $\mathrm{Ar}$ [20]. When a methane fuel $\left(\mathrm{Sc}_{\mathrm{F}}<1\right)$ is diluted with $\mathrm{N}_{2}[21]$, such a stationary lifted flame could exist in the developing region of a jet, with the liftoff height increasing monotonically with jet velocity. 
We report here the flame behavior of a nitrogen-diluted methane jet in a coflow, the liftoff height of which decreased and then increased with fuel jet velocity (hereafter called U-shaped behavior). Although decreasing and increasing liftoff height behaviors were observed for autoignited lifted flames from binary fuel mixtures with significantly different diffusivities (such as $\mathrm{CH}_{4} / \mathrm{H}_{2}$ and $\mathrm{CO} / \mathrm{H}_{2}$ ) under very high initial temperatures [22], such a non-monotonic liftoff height behavior has not been reported previously under ambient initial temperature conditions. We observed stationary lifted flames with decreasing and increasing liftoff height behaviors and elucidated the underlying physical mechanism using a numerical simulation.

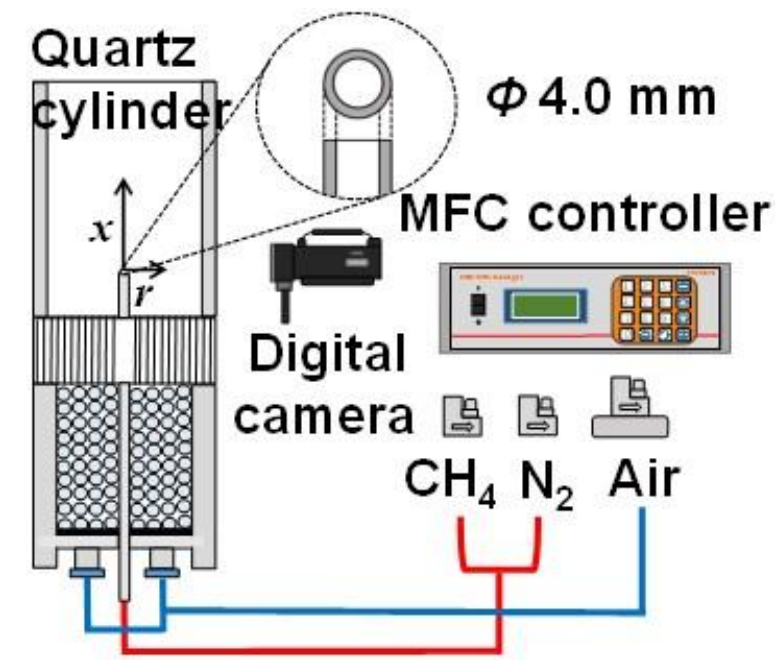

Fig. 1. Schematic of experimental setup.

\section{Experiment and numerical simulation}

The experimental apparatus consisted of a coflow jet burner, a flow system, and a visualization setup, as schematically shown in Fig. 1. A fuel tube with $600 \mathrm{~mm}$ in length and $D=4.0 \mathrm{~mm}$ in diameter was used to obtain fully developed velocity profile. A cylindrical quartz cylinder with i.d. $93 \mathrm{~mm}$ and a length of $400 \mathrm{~mm}$ was used for coflow. Air passed through a series of fine meshes and a ceramic honeycomb to generate a uniform flow. The fuel nozzle protruded $0.5 \mathrm{~cm}$ from the coflow outlet. The coflow air velocity $V_{\mathrm{CO}}$ was fixed at 
$7 \mathrm{~cm} / \mathrm{s}$. Analytical-grade methane ( $>99.99 \%$ purity) with $\mathrm{N}_{2}(99.95 \%$ purity) was used as the fuel. The flow rates were controlled by mass flow controllers and flow manager software. The nominal accuracies of the full-scale flow rates were within $1.0 \%$. Experiments were conducted with the Reynolds numbers in the range of $39.8 \leq \operatorname{Re}_{\mathrm{D}} \equiv U_{0} D / v \leq 224.0$ to ensure a laminar fuel stream, where $U_{0}$ is the initial fuel jet velocity and $v$ is the kinematic viscosity.

Liftoff heights were measured using a digital camera (Nex-VG20; 16.1 megapixels and 60 fps) attached to a two-axis translation stage. Matlab-based software was used to analyze the images, and the flame edge was defined as the brightest locus in the converted grayscale images.

To simulate lifted flames, time-dependent, axisymmetric governing equations in the cylindrical-coordinate $(r, x)$ were solved using the OpenFORM-based laminarSMOKE code for the mass, momentum, species, and energy equations [23-25]. The time integration and spatial discretization methods used were the implicit Eulerian scheme and second-order Gaussian central difference scheme, respectively. Molecular diffusion by concentration gradient and secondary diffusion of Soret effect were considered, while Dufour effect was neglected. The radiative heat loss was mainly from $\mathrm{CH}_{4}, \mathrm{CO}_{2}, \mathrm{H}_{2} \mathrm{O}$, and $\mathrm{CO}$, and the radiative heat flux using an optically thin approximation [26] was used. The computation dimensions in the radial and axial directions were 24- and 56-fold the nozzle radius with a grid size of $0.05 \mathrm{~mm}$. The simulation was conducted in an unsteady-state and then converges to a steadystate solution. The total CPU time was about 150 hours (60 core $2.0 \mathrm{GHz}$ cluster) for the initial mole fraction of $X_{\mathrm{F}, \mathrm{O}}=0.30$ and $U_{0}=16 \mathrm{~cm} / \mathrm{s}$. The calculation time was drastically reduced when changing either the velocity or fuel mole fraction. A uniform grid system was adopted since the liftoff height and reaction zone cannot be specified initially. The grid independence was checked by doubling the meshes. 

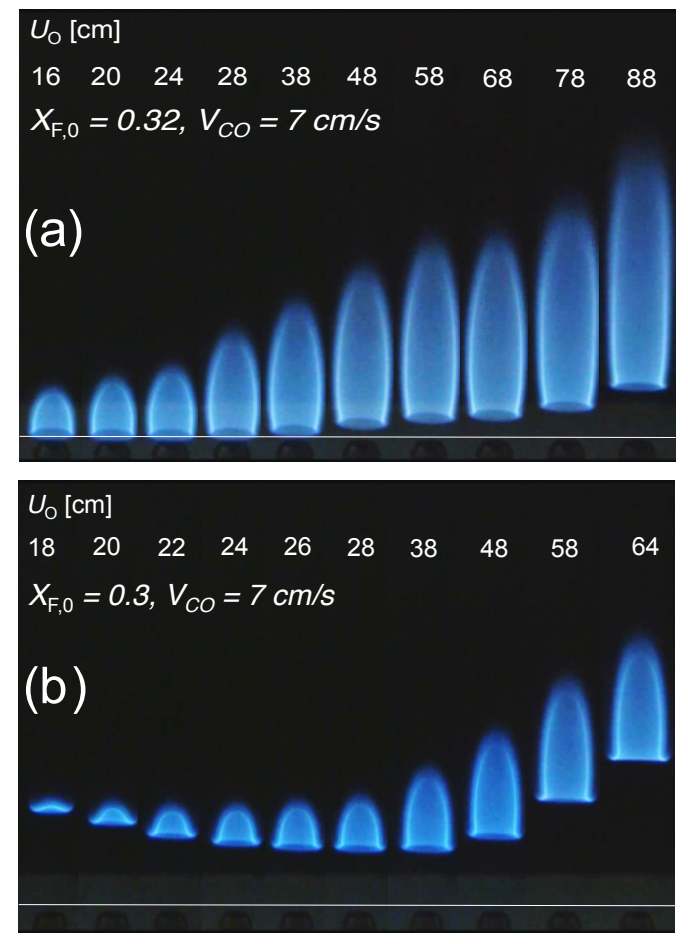

Fig. 2. Direct images of typical lifted flames with jet velocities; $X_{\mathrm{F}, 0}=0.32$ (a) and 0.30 (b).

When the fuel density is different from that of ambient air, the assignment of fuel velocity boundary condition has an appreciable effect on near nozzle flow field [27]. It is required that the fuel stream boundary condition should be specified inside a nozzle for an accurate prediction. In this regard, the fuel stream boundary conditions are assigned at $1.3 \mathrm{~cm}$ inside the nozzle with the fully developed velocity profile of pipe flow. For the nozzle wall, isothermal boundary conditions were employed and the nozzle-heating effect was not considered because our focus was on lifted flames, whose thermal thickness is typically $O(1$ $\mathrm{mm}$ ). Radiation is considered only in the gas-phase with the optical thin model [26]. A uniform velocity profile for coflow was assumed as the inlet condition. At the outlet, Neumann conditions were used for all scalar variables and velocity vectors. At the sidewalls, zero fluxes of scalar variables and normal velocity and a no-slip condition for axial velocity were applied. At the nozzle wall, a no-slip condition for velocities and zero fluxes of scalar 
variables were applied. The skeletal reaction mechanism [28] based on GRI v.3.0 with 30 species and 184 reactions [29] was adopted. Note that a two-step global reaction mechanism [30] was also tested. Although there was a difference between the two predicted liftoff heights, both mechanisms predicted the U-shaped behavior. This is because the buoyancy effect is mainly governed by the diffusion flame and heat release.

\section{Results and discussion}

\subsection{Stationary lifted flames}

Figure 2 shows direct images of typical lifted flames with $U_{0}$ for $X_{\mathrm{F}, 0}=0.32$ and 0.30 . For $X_{\mathrm{F}, 0}=0.32$ (a), the flame was attached to the nozzle at relatively small fuel jet velocities and changed to a lifted flame with $U_{0}$, exhibiting a monotonic increase in the liftoff height, $H_{\mathrm{L}}$, with jet velocity. For $\mathrm{X}_{\mathrm{F}, 0}=0.30$, the flame was lifted at small $U_{0}$ values and the liftoff height decreased and then increased with $U_{0}$, exhibiting non-monotonic U-shape behavior. Such a decreasing liftoff height with jet velocity has never been reported previously and is the focus of the present study. Although not clear from the images, the edges of the lifted flame exhibited tribrachial structures visible to the naked eye, with a bright inner rich premixed flame and a small outer lean premixed flame wing and a faint blue diffusion flame, all extending from the tribrachial point.

Figure 3 presents variations in liftoff height with fuel jet velocity at several fuel mole fractions. A stable flame was not observed for $X_{\mathrm{F}, 0}<0.30$. For $X_{\mathrm{F}, 0} \geq 0.34$, the flame was attached to the nozzle and liftoff/blowoff was not observed within the flow capacity limit.

The jet developing length $Z_{\text {free }}$ is plotted; this was estimated from free jet theory [31], corresponding to the axial distance balancing the centerline velocity of the jet $U_{\mathrm{CL}}$ and the maximum nozzle exit velocity $2 U_{0}$ assuming the Poiseuille flow. Thus, the axial distance $z<$ 
$Z_{\text {free }}\left(z>Z_{\text {free }}\right)$ corresponds to the developing (developed) region of a jet. This was estimated to be $Z_{\text {free }} / D=0.0165 \times \operatorname{Re}_{\mathrm{D}}[31]$.

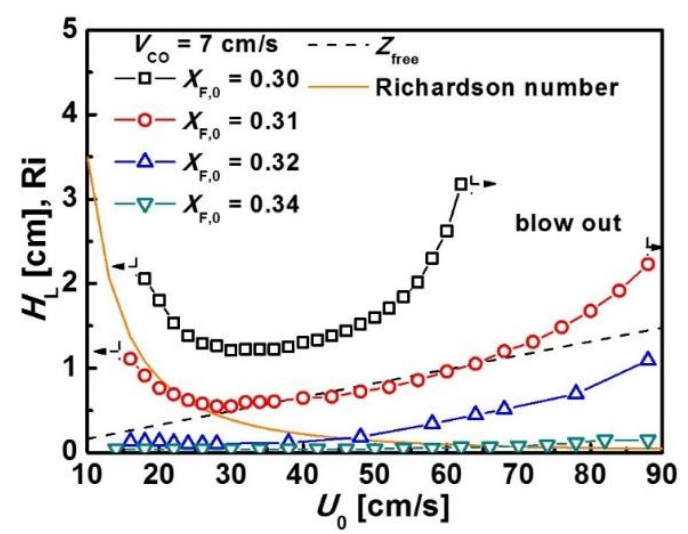

Fig. 3. Liftoff height versus fuel jet velocity at various fuel mole fractions.

For small jet velocities, the buoyancy effect predominates over convection [21], which can be represented as the Richardson number $\mathrm{Ri}=\left(\rho_{\mathrm{F}}-\rho_{\mathrm{b}}\right) g D / \rho_{\mathrm{F}} U_{0}^{2}$, where $\rho_{\mathrm{b}}$ is the burnt gas density of a stoichiometric mixture of fuel and air streams and $\rho_{\mathrm{F}}$ is the fuel stream density. $Z_{\text {free }}$ and Ri are plotted as black dotted and orange solid lines, respectively. Note that Ri decreases appreciably with $U_{0}$, implying that the buoyancy effect can be significant at small jet velocities.

For $X_{\mathrm{F}, 0}=0.34$, the flame was nozzle-attached for all jet velocities tested. For $X_{\mathrm{F}, 0}=0.32$, the flame was nozzle-attached for small $U_{0}$ values and gradually transitioned to a lifted flame such that it was difficult to identify a liftoff velocity. The liftoff height increased with jet velocity monotonically. Note that these liftoff heights are smaller than $Z_{\text {free }}$. Such behavior is similar to those reported previously [21], where a stable lifted nitrogen-diluted methane jet flame was observed in the jet-developing region even though $\mathrm{Sc}_{\mathrm{F}}<1$. This does not contradict the prediction of non-existence of a stable lifted flame in a free jet for $\mathrm{Sc}_{\mathrm{F}}<1$, as it was for a lifted flame in the developed region of a coflow jet. 
For $X_{\mathrm{F}, 0}=0.30$ and 0.31 , the flame was lifted at small velocities, and the liftoff height decreased with $U_{0}$ and then increases (U-shaped behavior). At very small and large $U_{0}$ values, a flame blowout was observed (indicated by arrows). The liftoff heights were larger than $Z_{\text {free, }}$ (especially for $X_{\mathrm{F}, 0}=0.30$ ), such that a stationary lifted flame was observed even in a developed jet region for $\mathrm{Sc}_{\mathrm{F}}<1$. Such a decreasing liftoff height behavior with jet velocity has not been reported previously.

The large Richardson numbers at small jet velocities suggest an important role for buoyancy in the lifted flames. To examine this, a numerical simulation was conducted for $X_{\mathrm{F}, 0}$ $=0.30$ with and without considering the buoyancy effect caused by the burnt gas along with the fuel, which is lighter than air. The heat release rate (HRR) contours from the simulation are presented in Fig. 4 for $U_{0}=20$ and $48 \mathrm{~cm} / \mathrm{s}$. When considering the buoyancy, lifted flames can be observed at both $U_{0}=20$ and $48 \mathrm{~cm} / \mathrm{s}$, while nozzle-attached flames are predicted when the buoyancy is not considered. This result emphasizes the role of buoyancy in stabilizing lifted flames at small jet velocities. In cases with a monotonic increase in $H_{\mathrm{L}}$ with $U_{0}$, the mechanism for such lifted flames was examined in detail previously [21]. Thus, the present study focuses on the U-shaped behavior.

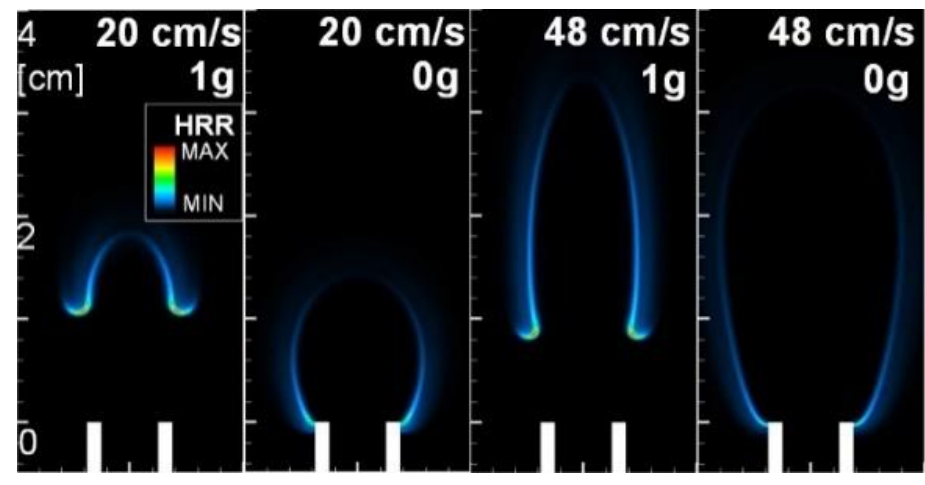

Fig. 4. Heat release rate contours from simulation with ( $1 \mathrm{~g})$ and without $(0 \mathrm{~g})$ considering buoyancy at $U_{0}=20$ and $48 \mathrm{~cm} / \mathrm{s}$ for $X_{\mathrm{F}, 0}=0.30$.

The temperature profiles, HRR, and several species mass fractions as a representative case 
of U-shaped behavior are shown in Fig. 5 for $U_{0}=20 \mathrm{~cm} / \mathrm{s}$ and $X_{\mathrm{F}, 0}=0.30$, with consideration of the buoyancy effect. Although not shown, the profiles are qualitatively similar for other jet velocities.

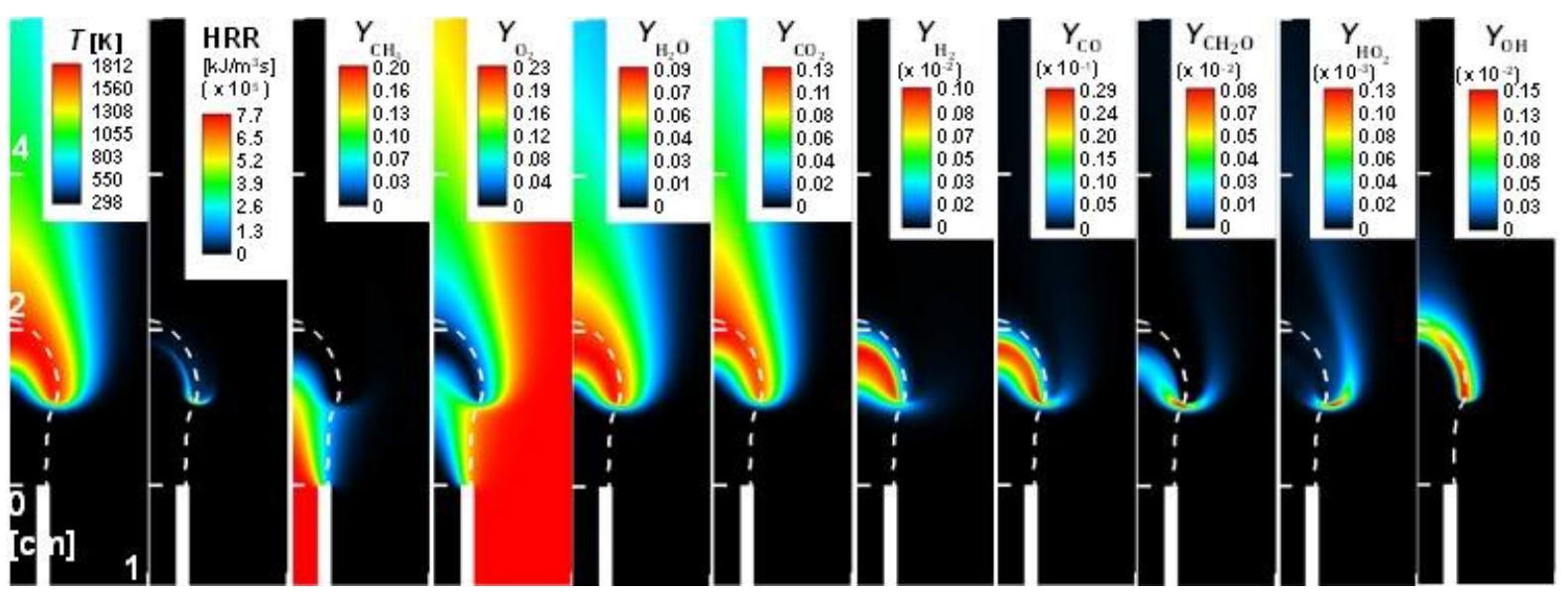

Fig. 5. Temperature, heat release rate, and mass fraction profiles of a lifted flame simulated for $U_{0}=20 \mathrm{~cm} / \mathrm{s}$ and $X_{\mathrm{F}, 0}=0.30$.

The stoichiometric contours are shown as white dashed lines based on ref. [32]. The temperature profile shows that maximum temperatures exist along the stoichiometric contour. A brief discussion on chemistry is presented to understand better the numerical results on radicals, intermediate, and product species, which occur at different locations. $\mathrm{OH}$ radicals, which are typically maximum along a diffusion flame, are also maximum along the stoichiometric contour. HRR is maximum along the lean and rich premixed flame wings, and peaks at the stoichiometry. The HRR and $\mathrm{OH}$ profiles clearly indicate a tribrachial edge flame structure. Methane is diluted along the mixing layer and partially oxidized to $\mathrm{CO}$ and $\mathrm{H}_{2}$, which are consumed in the diffusion flame. The consumption of $\mathrm{CH}_{4}$ produces $\mathrm{CH}_{3}$ via the abstraction of $\mathrm{H}$ near the reaction zone, while $\mathrm{OH}$ radical is formed by the dominant chainbranching reaction $\left(\mathrm{H}+\mathrm{O}_{2} \rightarrow \mathrm{O}+\mathrm{OH}\right)$ in the high-temperature region, together with $\mathrm{H}$ and $\mathrm{O}$ 
radicals. Subsequently, $\mathrm{CHO}$ is formed and then converted to $\mathrm{CO}$ and $\mathrm{H}_{2}$. Major radicals of $\mathrm{OH}, \mathrm{H}$ and $\mathrm{O}$ (not shown) are maximum near the diffusion flame. Oxygen diffuses into the fuel stream through the mixing layer, is consumed in the inner rich premixed flame, and subsequently diffuses into the axial region over the premixed flame wing to form a diffusion flame. Species relevant to low-temperature kinetics of $\mathrm{CH}_{2} \mathrm{O}, \mathrm{HO}_{2}$ and $\mathrm{H}_{2} \mathrm{O}_{2}$ (not shown) appear near the premixed flame wing, which is due to the abundance of $\mathrm{O}_{2}$ from coflow air. Finally, the profiles of the major products of $\mathrm{H}_{2} \mathrm{O}$ and especially $\mathrm{CO}_{2}$, are similar to that of temperature.

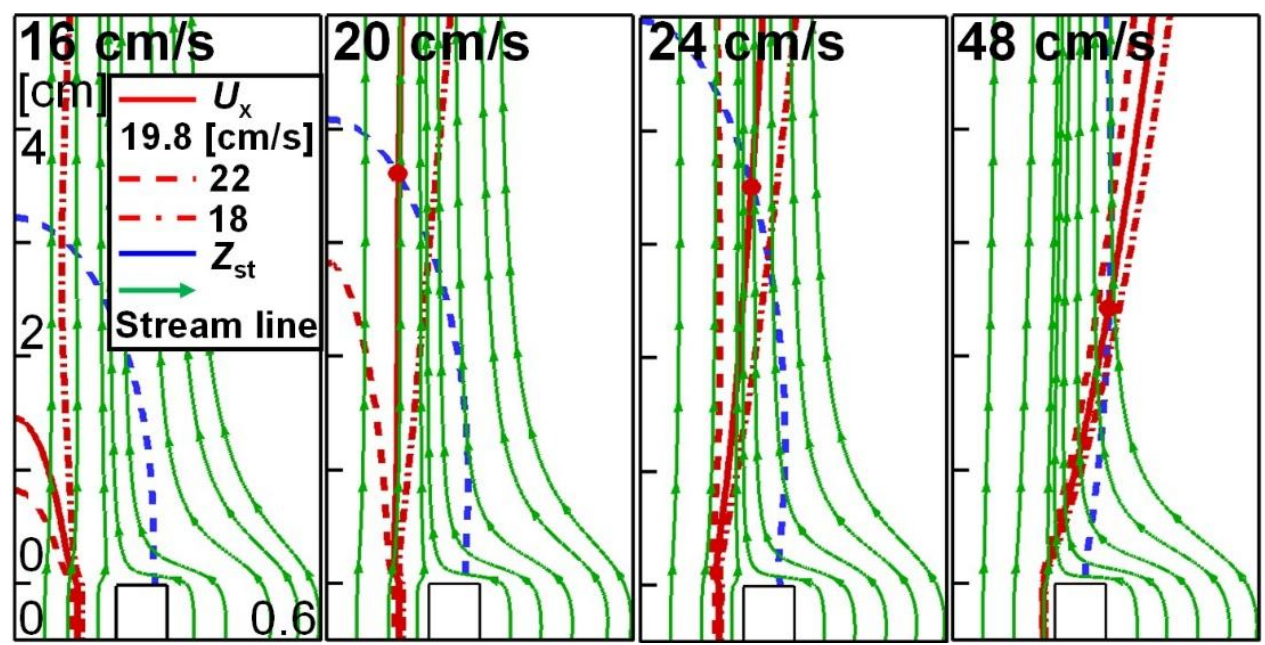

Fig. 6. Streamlines (green), stoichiometric mixture fraction contours (dashed blue), and isovelocity contours corresponding to the stoichiometric laminar burning velocity at various fuel jet velocities for a cold jet with $X_{\mathrm{F}, 0}=0.30$.

\subsection{Stabilization mechanism of lifted flames}

Lifted flame stabilization has often been analyzed for cold flow in free jets [1-3]. A cold flow field was simulated by varying $U_{0}$ for $X_{\mathrm{F}, 0}=0.3$ (Fig. 6). The blue dotted line is the stoichiometric mixture fraction contour and the red solid line is the iso-axial velocity contour corresponding to a stoichiometric laminar burning velocity $S_{\mathrm{L}}{ }^{0}=19.8 \mathrm{~cm} / \mathrm{s}$ (calculated from GRI 3.0 [30]) along with at 22 and $18 \mathrm{~cm} / \mathrm{s}$ for comparison, and the green solid lines are the 
streamlines. For $U_{0}=16 \mathrm{~cm} / \mathrm{s}$, there is no cross point between the stoichiometry line and isovelocity contour for $S_{\mathrm{L}}^{0}$. For $U_{0}=20 \mathrm{~cm} / \mathrm{s}$, the cross-point exists near the centerline. As $U_{0}$ increases, the cross-point moves toward the upstream. This decreasing trend of liftoff height with jet velocity qualitatively agrees with the results of the analytical similarity solutions in a free jet [19], where a decreasing liftoff height was predicted for $\mathrm{Sc}_{\mathrm{F}}<1$. Assuming that the edge propagation speed (taken as, for example, the laminar burning velocity) is reasonably uniform, when a flame edge is perturbed toward the upstream (downstream) along the stoichiometric contour, because the local axial velocity decreases (increases), the edge will propagate upstream (downstream), as can be judged from the iso-velocity contours of 18 and $22 \mathrm{~cm} / \mathrm{s}$. Thus, such a flame is unstable and a stationary lifted flame is not expected to exist.

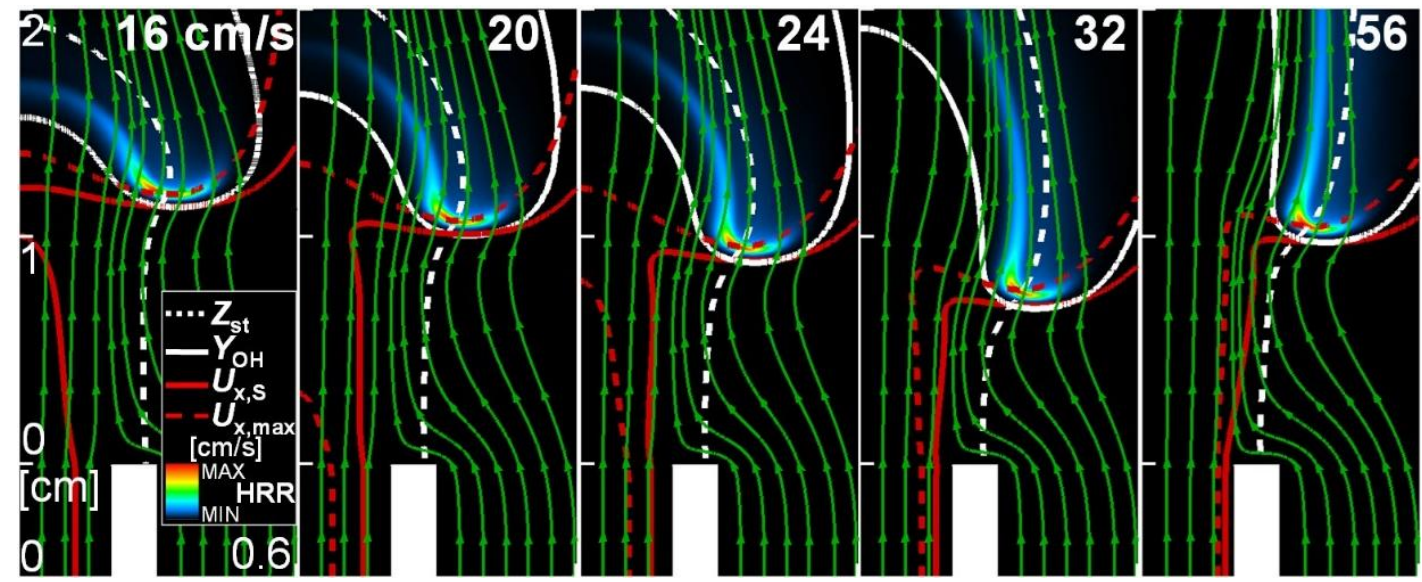

Fig. 7. Behavior of lifted flame with jet velocity simulated numerically in a nitrogen-diluted methane jet flame with $X_{\mathrm{F}, 0}=0.3 . Z_{\mathrm{st}}$ is the stoichiometric mixture fraction (dashed white), $Y_{\mathrm{OH}}$ is the $\mathrm{OH}$ mass fraction of $6.5 \times 10^{-7}$ (while solid), $U_{\mathrm{x}, \mathrm{S}}$ is the axial velocity corresponding to $S_{\mathrm{L}}^{0}$ (red solid), and $U_{\mathrm{x}, \max }$ is the axial velocity corresponding to maximum heat release.

The above kinematic view based on cold flow cannot predict a stable lifted methane flame. To further examine the U-shaped behavior, reacting flows were simulated considering the buoyancy effect at various jet velocities for $X_{\mathrm{F}, 0}=0.30$ (Fig. 7). Color-coded heat release rate profiles, streamlines (green), stoichiometric mixture fraction contours $\left(Z_{\text {st }}\right)$ (dashed white), 
iso-contours of the $\mathrm{OH}$ mass fraction (white solid) of $Y_{\mathrm{OH}}=6.5 \times 10^{-7}$, and the iso-axial velocity $U_{\mathrm{x}}$ contours corresponding to $S_{\mathrm{L}}{ }^{0}$ of $U_{\mathrm{x}, \mathrm{S}}$ (red solid), and $U_{\mathrm{x}}$ corresponding to maximum heat release, $U_{\mathrm{x}, \max }$ (red dotted) contours are shown. The results for $U_{\mathrm{x}, \mathrm{S}}$ and $Y_{\mathrm{OH}}$ (considered as the edge of the reaction zone) are reasonably close near the tribrachial point.

For $U_{0}=16 \mathrm{~cm} / \mathrm{s}$, the $U_{\mathrm{x}, \mathrm{S}}$ contours are disconnected. Due to small jet velocity, the axial velocity from the jet initially decays and is then accelerated by the buoyancy-induced upward flow, as shown by the inward deflection of streamlines outside of the nozzle region. As $U_{0}$ (jet momentum) increases, the cross-point between $Z_{\mathrm{st}}$ and $U_{\mathrm{z}, \mathrm{S}}$ moves upstream as the relative importance of buoyancy decreases (manifested by the rapid decrease in the Richardson number in Fig. 3), thereby the acceleration effect by the buoyancy on axial velocity diminishes, thus decreasing the liftoff height. At further increased $U_{0}$, the jet momentum dominates such that the liftoff height increases with $U_{0}$.

Axial and radial flow speeds with axial distance along the stoichiometric mixture fraction contour $Z_{\mathrm{Zst}}$ are shown in Fig. 8. The dotted line in (a) denotes the axial speed near the tribrachial point and the arrow indicates the trend with increasing $U_{0}$. The axial location for the minimum axial velocity decreases up to $U_{0}=32 \mathrm{~cm} / \mathrm{s}$ and then increases with higher $U_{0}$ values. The axial velocity along the stoichiometric contour for large $U_{0}$ increases and then decreases due to a flow redirection effect near a minimum and then accelerates due to gas expansion. At small $U_{0}$ values, the flow redirection effect is less conspicuous. For all the cases, local maximum and then minimum $U_{z}$ exists, which stabilizes the lifted flames. Note that the minimum axial velocities are less than $S_{\mathrm{L}}{ }^{0}$. The radial velocity is inward (negative) at small $Z_{\mathrm{Zst}}$ due to entrainment and outward (positive) by gas expansion, peaks, and then decreases to a negative value after further entrainment. As compared with cold flow simulation using the kinematic argument by perturbing flame location along the 
stoichiometric contour to evaluate flame stability, such a perturbation in the reacting flow case alters the upstream cold flow due to a change in buoyancy effect and entrainment when the flame location is perturbed.

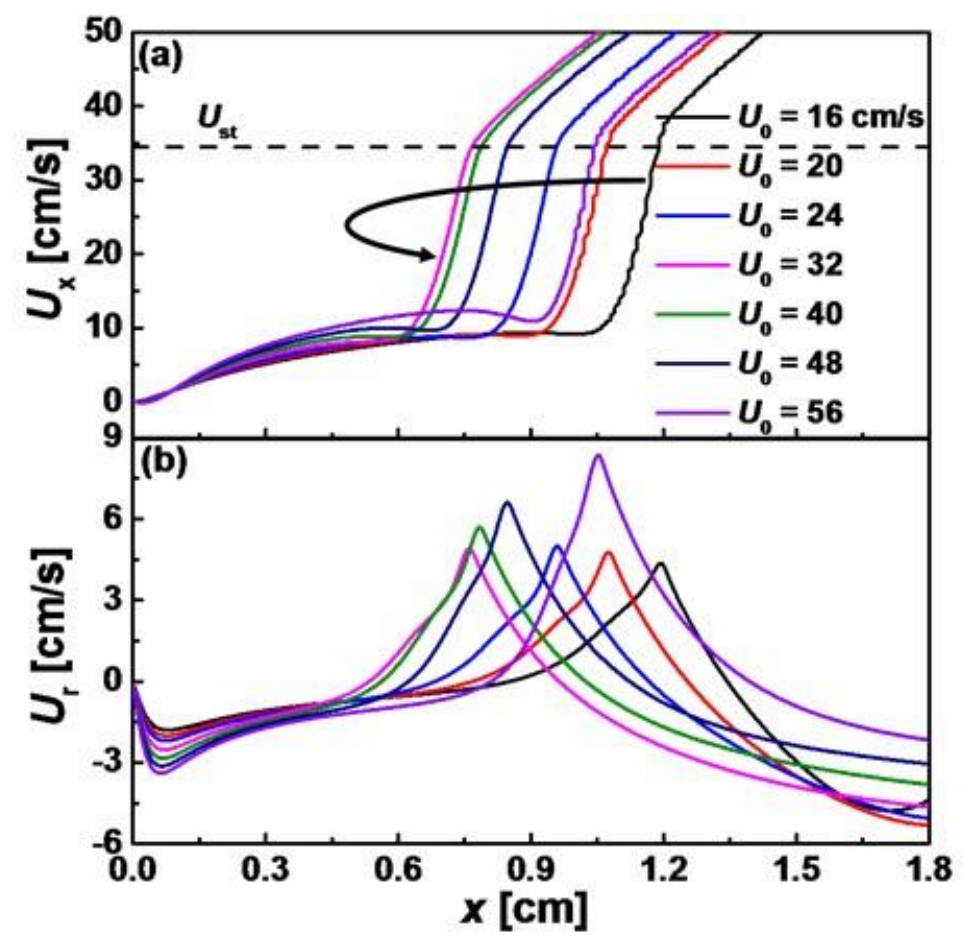

Fig. 8. Axial (a) and radial (b) flow speeds with axial distance along the stoichiometric mixture fraction contour in terms of jet velocity.

It is interesting to note that the minimum axial speed along the stoichiometric contour was about $10 \mathrm{~cm} / \mathrm{s}$, which is smaller than the laminar burning velocity of $19.8 \mathrm{~cm} / \mathrm{s}$. The preheated zone thickness $\left(\delta_{T}\right)$ in front of the tribrachial point can be estimated from $\delta_{T}=\left(T_{\mathrm{ad}}-T_{\mathrm{u}}\right) /(d T / d x)_{\mathrm{MAX}}$, where $T_{\mathrm{st}}$ and $T_{\mathrm{u}}$ are the stoichiometric adiabatic flame temperature and unburned temperature, respectively. For $X_{\mathrm{F}, 0}=0.3$, it is estimated to be 0.68 $\mathrm{mm}$. When the location of the maximum heat release rate is taken as the tribrachial point, this length approximately corresponds to that with $U_{\mathrm{z}}=S_{\mathrm{L}}{ }^{0}$. Note that $U_{\mathrm{z}}$ at the tribrachial point is nearly $34.5 \mathrm{~cm} / \mathrm{s}$, which is smaller than the theoretical limit $\left(S_{\mathrm{L}}^{0} \sqrt{\rho_{\mathrm{u}} / \rho_{\mathrm{b}, \mathrm{st}}}=51.3 \mathrm{~cm} / \mathrm{s}\right)[10]$. 


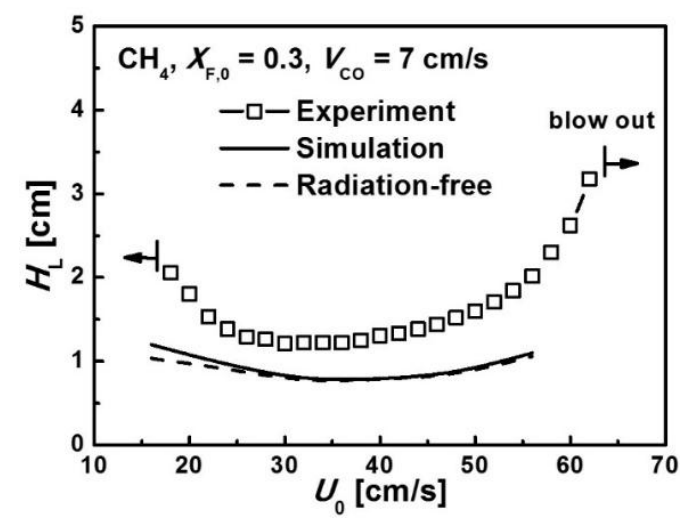

Fig. 9. Experimental and simulated liftoff heights with jet velocity for $X_{\mathrm{F}, 0}=0.3$.

Experimental and simulated (considering buoyancy) liftoff heights with jet velocity are compared in Fig. 9 for $X_{\mathrm{F}, 0}=0.3$. The solid and dotted lines are the predictions simulated with and without consideration of radiation effects, respectively. In the simulation, the liftoff height was defined as the axial distance corresponding to the maximum heat release. Experimentally, the liftoff height was determined at the maximum luminosity in the premixed flame wings. Thus, the two definitions are comparable. The simulated liftoff heights underestimate those determined experimentally. The difference between the measured and predicted liftoff heights could be partially attributed to uncertainties in the simulation, for example, the treatment of honeycomb for the coflow (a uniform coflow condition was assumed while it has an array of small square ducts), assignment of fully developed velocity profile for the fuel, and the adoption of the skeleton mechanism. However, the qualitative simulation results are in reasonable agreement with the experimental finding of decreasing and increasing liftoff height with jet velocity.

\section{Conclusion}

Experimental and numerical studies were conducted by varying the fuel jet velocity in 
laminar lifted nitrogen-diluted methane coflow-jet flames. Two flame types were observed: nozzle-attached flames and stationary lifted flames. The results revealed that even for Schmidt numbers less than unity, stationary lifted flames could exist in the jet-developed region as well as the jet-developing region. Liftoff heights decreased and then increased with fuel jet velocity (U-shaped behavior) for $0.30 \leq X_{\mathrm{F}, 0} \leq 0.32$, but increased monotonically with fuel jet velocity for $0.32 \leq X_{\mathrm{F}, 0}<0.34$ in the jet-developing region. The flames were blown off for $X_{\mathrm{F}, 0}<0.30$ and attached to the nozzle for $X_{\mathrm{F}, 0}>0.34$.

To elucidate the physical mechanism underlying the U-shaped behavior, numerical simulations for reacting jets were conducted by adopting a skeletal mechanism. The Ushaped behavior was found to be related to the buoyancy. At small jet velocities, the relative importance of buoyancy over convection was strong and the flow field was accelerated in the downstream region to stabilize the lifted flame. As the jet velocity increased, the relative importance of buoyancy decreased and the liftoff height decreased. As the jet velocity further increased, flame stabilization was controlled by convection and the liftoff height increased. These are the stabilization mechanisms of lifted flames that exhibit the U-shaped behavior.

\section{Acknowledgements}

This work was supported by the National Research Council of Science \& Technology (NST) grant by the Korea government (MSIP) No.CRC-14-01-ETRI. MSC and SHC were supported by Clean Combustion Research Center (CCRC), King Abdullah University of Science and Technology (KAUST).

\section{References}

[1] S.H. Chung, B.J. Lee, Combust Flame 86 (1991) 62-72.

[2] B.J. Lee, S.H. Chung, Combust Flame 109 (1997) 163-172. 
[3] B.J. Lee, M.S. Cha, S.H. Chung, Combust Sci Technol 127 (1997) 55-70.

[4] Y.S. Ko, S.H. Chung, Combust Flame 118 (1999) 151-163.

[5] S.H. Chung, Proc Combust Inst 31 (2007) 877-892.

[6] Y.C. Chen, R.W. Bilger, Combust Flame 122 (2000) 377-399.

[7] N. Peters, Prog Combust Inst 10 (1984) 319-339.

[8] J.W. Dold, Combust Flame 76 (1989) 71-88.

[9] P.N. Kioni, B. Rogg, K.N.C. Bray, A. Liñán, Combust Flame 95 (1993) 276-290.

[10] G.R. Reutsch, L. Vervisch, A. Liñán, Phys Fluids 6(7) (1995) 1447-1454.

[11] J. Buckmaster, J Eng Math 31 (1997) 269-284.

[12] J. Daou, A. Liñán, Combust Theory Modelling 2 (1998) 449-477.

[13] V.N. Kurdyumov, N. Matalon, Proc Combust Inst 31 (2007) 909-917.

[14] J.S. Park, D.J. Hwang, J. Park, J.S. Kim, S. Kim, S.I. Keel, T.K. Kim, D.S. Noh, Combust Flame 146 (2006) 612-619.

[15] M. Short, Y. Liu, Combust Theory Modelling 8 (2004) 425-447.

[16] S.H. Won, S.H. Chung, M.S. Cha, B.J. Lee, Proc Combust Inst 28 (2000) 2093-2099.

[17] S.H. Won, J. Kim, M.K. Shin, S.H. Chung, O. Fujita, T. Mori, J.H. Choi, K. Ito, Proc Combust Inst 29 (2002) 37-44.

[18] S.H. Yoon, J.K. Han, J. Park, J.H. Yun, S.I. Keel, Combust Flame 158 (2011) 1960-1969.

[19] S. Ghosal, L. Vervisch, Combust Flame 123 (2001) 646-655.

[20] R.H. Chen, A. Kothawala, M. Chaos, L.P. Chen, Combust Flame 141 (2006) 469-472.

[21] S.H. Won, J. Kim, K.J. Hong, M.S. Cha, S.H. Chung, Proc Combust Inst 30 (2005) 339347.

[22] B. C. Choi, S. H. Chung, Combust Flame 159 (2012) 1481-1488.

[23] A. Cuoci, A. Frassoldati, T. Faravelli, E. Ranzi, Energy Fuels 27(12) (2013) 7730-7753.

[24] A. Cuoci, A. Frassoldati, T. Faravelli, E. Ranzi, Combust Flame 160(5) (2013) 870-886.

[25] A. Cuoci, A. Frassoldati, T. Faravelli, E. Ranzi, Compter Phys Commun 192 (2015) 237264.

[26] Y. Ju, H. Guo, K. Maruta, F. Liu, J Fluid Mech 342 (1997) 315-334.

[27] Y. Xiong, M. S. Cha, S. H. Chung, Proc Combust Inst 35 (2015) 873-880.

[28] T.F. Lu, C.K. Law, Combust Flame 154 (2008) 761-774.

[29] G. P. Smith, D. M. Golden, M. Frenklach, N. W. Moriarty, B. Eiteneer, M. Goldenberg, C. T. Bowman, R. K. Hanson, S. Song, W. C. Gardiner Jr., V. V. Lissianki, Z. Qin, GRI-MECH 3.0, 1999, < http://www.me.berkeley.edu/gri mech/>.

[30] G. Boudier, 2S-CM2 Mech, 2017, http://www.cerfacs.fr/cantera/mechanisms/meth. php\#bfer.

[31] D.S. Lee, K.D. Kihm, S.H. Chung, J Fluid Eng Trans ASME 119 (1997) 716-718.

[32] R.W. Bilger, Proc Combust Inst 22 (1988) 475-488. 